\title{
PRIMARY AMINE IMPLANTATION ONTO POLYPROPYLENE SURFACES FROM MELAMINE AND UREA RF PLASMAS
}

\author{
R. GANAPATHY, X. WANG, F. DENES, and M. SARMADI* \\ Department of Environment Textiles and Design and \\ Engineering Research Center for Plasma-Aided Manufacturing, \\ University of Wisconsin-Madison, WI 53706
}

\begin{abstract}
The possibility of generating tailored surface characteristics (adhesion, biocompatibility, wettability, etc.) from plasma modified surfaces by derivatization and grafting reactions, opens up new possibilities for the creation of advanced materials. Implantation of reactive amine (primary amine) functionalities onto synthetic polymeric surfaces under cold plasma conditions - one of the potential approaches to surface functionalization has been the subject of numerous investigations of recent years. It has been shown that ammonia plasmas do not implant primary amine groups efficiently and consequently, a large number of amine-group containing compounds were tested as alternatives. However, the low volatilities of many of potential aminating agents limit considerably their plasma processing. In this contribution a novel approach of surface amination of PP samples from melamine and urea precoated surfaces is presented. ESCA, ATR-FTIR and ex-situ post plasma grafting reaction data indicate that simultaneous plasma induced evaporation, fragmentation and primary amine implantation processes can be successfully developed. The surface primary-amine concentrations were evaluated by chemical derivatization technique, and the influence of plasma treatment time on the amine group concentrations was investigated.
\end{abstract}

\section{INTRODUCTION}

Electric energy initiated cold plasma states arise when accidentally free electrons of a low pressure gas or a gaseous mixture are accelerated by electric or electromagnetic fields to a kinetic energy level at which ionization, excitation and molecular fragmentation processes are induced, associated with the generation of electromagnetic radiation. This state of the matter is characterized by the simultaneous presence of electrons, ions of either polarity, neutral atoms and gas molecules, mono and

\footnotetext{
* Please address all correspondence to M. Sarmadi.
} 
multiple free-radicals and excited species in lower or any higher states, and photons. The relative ratios and abundance of these species depend on the external (pressure in the reactor, electric power dissipated to the electrodes, temperature of the surfaces which limit the plasma, etc.) and internal (electron and charged particle energy distribution, charged and neutral particle densities, etc.) plasma parameters. The number of positively and negatively charged carriers usually are equal and consequently the system is neutral as a whole. Based on this global neutrality plasmas are considered as the fourth state of the matter. The plasma state can be associated with the high energy content of the matter. At very high temperatures, like over $8,000^{\circ} \mathrm{K}$ all atoms and molecules are ionized and both the electrons and ions have very high energies; this states represent the so called "true plasmas" or equilibrium or "hot plasmas". It is estimated that over $99 \%$ of the matter of the Universe is in the plasma state. All active celestial bodies, e.g. our Sun, represent true plasmas. The interstellar spaces are considered rarefied plasmas, as well. At much lower energy contents the degrees of ionization are small (1-5\%) and the atomic and molecular charged- and neutral-species have low energies while the electrons have a relatively high energy content. These states of the matter are usually recognized as "cold plasmas" or non-equilibrium plasmas, and due to the relatively low energy contents of composing species these discharges are suitable for modifying organic matter. The plasma state can be generated by mechanical, chemical and electrical energies. However, plasma is loosing energy towards the walls which confine it through collision and radiation processes, and as a consequence energy must be injected into the system continuously in order to sustain the discharge. The most convenient way to supply energy on a continuous manner is by using electrical energy, and consequently electrical energy initiated discharges are the most common plasmas.

The active species of plasmas exhibit specific energy distributions. A typical electron energy distribution function for instance, is presented in Fig. 1. One can observe that a small number of electrons have relatively high energies $(5-8 \mathrm{eV})$ while the bulk of the electrons belong to a low electron-energy range (0.5-4 eV). Since the ionization potentials (the work required to remove a given electron from its atomic orbit) required for the formation of mono-ions from atoms of common organic compounds ( $C=11.26 ; \quad H=13.6 ; \quad O=13.61$; $\mathrm{N}=14.53 ; \mathrm{Cl}=12.96 ; \mathrm{S}=10.36 \mathrm{eV}$, etc.) belong to the tail region of the energy

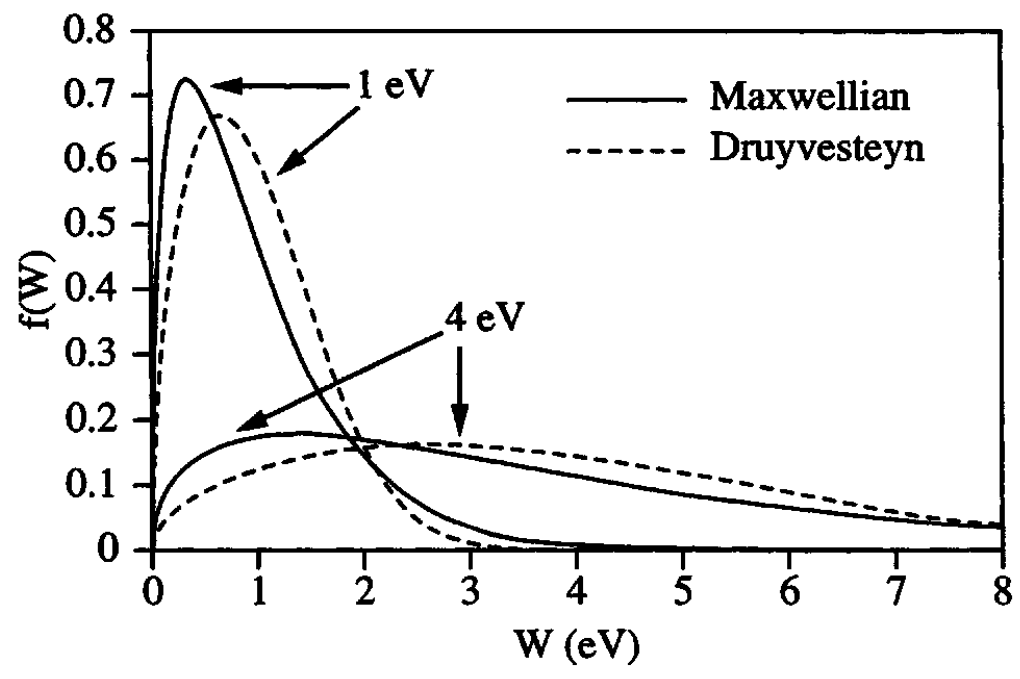

Fig. 1 Schematic Maxwellian and Druyvesteyn Energy Distribution Function for Electrons. 
distribution, the low degrees of ionization of cold plasmas are obvious. It also can be noticed that the 0-5 eV energy spectrum of cold plasmas is intense enough to cleave almost all chemical bonds involved in organic structures (Table 1) and to create active molecular fragments (e.g. free radicals). Relatively higher energies are required only by the dissociation of double and triple bonds and by the formation of corresponding poly free radicals. As a consequence, all organic and elemental organic derivatives can easily be modified and converted into macromolecule structures (on the surfaces which limit the plasma state) through the recombination of plasma generated active molecular fragments. It also can be understood why higher energies of active species of plasmas will generate macromolecular structures based on unsaturated bonds and three-dimensional networks (crosslinked structures).

Table 1. Bond Energies and Enthalpies of Formation of Free Radicals

\begin{tabular}{|c|c|c|c|c|}
\hline \multirow{2}{*}{\multicolumn{2}{|c|}{ Bond Energies (eV) }} & \multicolumn{3}{|c|}{ Enthalpies of Formation of Free Radicals } \\
\hline & & & $\mathrm{KJ} / \mathrm{mol}$ & $\mathrm{eV}$ \\
\hline \multicolumn{5}{|c|}{ Diatomic Molecules } \\
\hline C-H & 3.5 & C-H. & 596.3 & 6.1 \\
\hline C-N & 7.8 & $\mathrm{CH}_{2}$. & 430.1 & 4.4 \\
\hline $\mathrm{C}-\mathrm{Cl}$ & 4.0 & $\mathrm{CH}_{3}$. & 146.0 & 1.5 \\
\hline C-F & 5.7 & $\mathrm{HC} \equiv \mathrm{C}$ & 566.1 & 5.8 \\
\hline $\mathrm{C}=\mathrm{O}$ & 11.2 & $\mathrm{HC}=\mathrm{CH}_{2}$. & 300.0 & 3.1 \\
\hline C-C & 6.3 & NH: & 325.3 & 3.6 \\
\hline \multicolumn{5}{|c|}{ Polyatomic Molecules } \\
\hline $\mathrm{C}=\mathrm{C}$ & 7.6 & $\mathrm{NH}_{2}$. & 185.4 & 1.9 \\
\hline $\mathrm{C} \equiv \mathrm{C}$ & 10.0 & .Ṣंi• & 456.6 & 4.7 \\
\hline $\mathrm{CH}_{3}-\mathrm{H}$ & 4.5 & SiCl: & 195.0 & 2.0 \\
\hline $\mathrm{C}_{2} \mathrm{H}_{5}-\mathrm{H}$ & 4.3 & $\mathrm{SiCL}_{2}$ : & -163.0 & -1.7 \\
\hline $\mathrm{CH}_{2} \mathrm{CH}-\mathrm{H}$ & 4.8 & $\mathrm{SiCl}_{3^{*}}$ & -318.0 & -3.3 \\
\hline \multirow[t]{2}{*}{ CHC-H } & 5.7 & $\mathrm{C}_{6} \mathrm{H}_{5}$. & 328.9 & 3.4 \\
\hline & & $\mathrm{C}_{6} \mathrm{~F}_{5}$ & -547.7 & 5.7 \\
\hline
\end{tabular}

Beside the plasma induced gas-phase processes and recombination mechanisms the active species of plasma interact and tailor continuously the original (reactor walls, inorganic, organic or polymeric substrates exposed to plasma) and self-created (plasma deposited micro or macromolecular structures) surface layers which limit the discharge. The balance between the active-species-driven recombination and decomposition reactions will control the intensities and predominance of surface functionalization, ablation or macromolecular-structure deposition-mechanisms. Due to the fact that the bulk of the active species of discharge have energies which overlap the whole energy range of 
chemical bonds involved in organic derivatives, the molecular structures of specific compounds (bond energies, enthalpies of formation of free radicals) will control the plasma induced fragmentation process. Even higher energies injected into the discharges (electric or electromagnetic energies dissipated to the electrodes) will influence mainly the absolute values of charged and neutral particle intensities and it will have a less significant influence on their relative ratios [1-7].

The interaction of reactive- and non-reactive-gas plasmas with polymeric substrates has been studied extensively [8-15]. The implantation of reactive amine group functionalities onto synthetic polymeric surfaces for tailoring characteristics like, reactivity, adhesion, dyeability, surface energy etc., is one of the promising possibilities in this area. In essence, $\mathrm{N}, \mathrm{H}$ and $\mathrm{C}$ based derivatives would be capable of incorporating amine (primary, secondary, tertiary, cyclic) and imine functionalities onto polymeric surfaces, under cold plasma conditions. These groups exhibit advanced basic character (nucleophilic agents) and promote consequently molecular interactions with acidic counterparts. However, due to the high instability (reactivity) of imines and secondary amines, primary amine functionalized surfaces remain the potential candidates for second stage ex-situ surface modification reactions (e.g. grafting mechanisms).

Early attempts to implant primary amine functionalities have been initiated from ammonia discharges. The plasma induced decomposition of ammonia has been studied for both theoretical and practical purposes [16-25], but the molecular fragmentation and recombination processes have still not been fully understood. It has also been found that ammonia plasmas does not produce primary amine implantation efficiently [26] and accordingly saturated and unsaturated amine-plasmas were suggested to be employed as an alternative[27-35]. Successful surface amination of various polymeric substrates were reported, however due to the diversity of plasma reactors, nature of plasma gases and experimental conditions direct comparison of results from these experiments is difficult. In order to increase the relative amount of surface-grafted- $\mathrm{NH}_{2}$ groups relative to the total $\mathrm{N}$-containing functionalities, the utilization of $\mathrm{NH}_{3} / \mathrm{H}_{2}$-plasmas was suggested [36] recently. It was demonstrated that the hydrogen atoms produced in the discharge can transform the grafted N-based groups into $\mathrm{NH}_{2}$ functionalities, and that after-glow conditions facilitate the primary amine group implantation processes.

It can be assumed that higher primary amine surface-densities could be achieved from multi-aminegroup containing starting components. However, some of the optimal potential candidates from this class of compounds exhibit low volatility (e.g. melamine, paraphenylenediamine, etc.) which would require specially designed plasma reactors and elaborate handling procedures. Thermal decomposi- 
tion mechanisms which are often associated with the vaporization processes and undesired amine depositions outside of plasma zones, make the control of plasma reactions difficult.

Recently an alternative method for surface modification of polymeric substrates from non-volatile compounds was suggested in our laboratories, which proposes the development of simultaneous evaporation and plasma-induced surface modification reactions. In essence the technique implies the exposure of non-volatile compound pre-coated polymeric substrates to inert-gas-plasma conditions. The vapor origin active species of the discharge permit the development of efficient surface functionalization reactions in the absence of a laborious reactant handling procedure. In this paper primary amine implantation onto polypropylene (PP) surfaces is investigated under the action of melamine (M) and urea (U)-RF-plasmas.

\section{EXPERIMENTAL}

Materials: Aldrich $99+\%, \mathrm{M}$ and $\mathrm{U}$ were used in all experiments. PP fabrics samples (diameter = $200 \mathrm{~mm}$ ) were acetone extracted to remove possible technical additives and stored under vacuum desiccator conditions until the plasma treatments were initiated. Liquid carbonic high purity argon (Ar) was used both for plasma decontamination procedures and for plasma treatment reactions. Aldrich toluene 2,4-diisocyanate (TDI), tetrahydrofuran (THF), polyethylene glycol (PEG-1000) and dibuthyl dilaureate (DD) were employed for the development of ex-situ post plasma grafting reactions. Acid Red 1 dye (AAKASH Chemicals \& Dye Stuffs Inc.) was employed to evaluate the surface densities of plasma-implanted primary amine groups.

Methods: Extracted and dried PP samples were $M$ and $U$ coated $\left(0.30-0.40 \mathrm{mg} / \mathrm{cm}^{2}\right)$ by immersing them into $1 \%$ water based solutions at $80^{\circ} \mathrm{C}$ and dried in vacuum oven consecutively. Each plasma treatment experiment was preceded by a decontamination procedure of the reactor by igniting argonplasma (RF-power: $200 \mathrm{~W}$; pressure: $200 \mathrm{mT}$; flow rate argon: $5 \mathrm{sccm}$ ) for ten minutes. The plasma induced molecular fragmentation of $\mathrm{M}$ and $\mathrm{U}$ were simulated at low energy electron mass spectrometry (LEE-MS) conditions (GC-Carlo Erba Fractovap 4162, MS Kratos MS-25, experimental conditions: column-fused silica, length- $30 \mathrm{~m}, \mathrm{ID}-0.32 \mathrm{~mm}$, coating- $5 \%$ phenyl and $95 \%$ vinyl polysiloxane, injector splitter temperature; $100^{\circ} \mathrm{C}$, temperature profile of the column; 1 minute at room temperature then heated up to $300^{\circ} \mathrm{C}$ at rate of $20^{\circ} \mathrm{C} / \mathrm{min}$., electron energy; $30 \mathrm{eV}$ ). Both starting components were run through the GC system in order to verify their purity. Surface atomic compositions of untreated and $\mathrm{M}$ - and U-plasma modified substrates were evaluated using $\mathrm{X}$-ray photoelectron spectroscopy (ESCA Perkin Elmer Physical Electronics 05400 Small Area System; Mg source; 15 kV; $300 \mathrm{~W}$; pass energy: $35 \mathrm{eV}$; angle: 45 degrees). The measurements involved C1s, O1s and N1s. 


\section{J. Photopolym. Sci. Technol., Vol.9, No.2, 1996}

Wettability of virgin and plasma treated samples were evaluated by using a computer aided CAHN Dynamic Contact Angle Analyzer (2x30 mm samples, elevator speed: $150 \mathrm{um} / \mathrm{s}$, humidity: 50\%, temperature: room temperature). Post plasma grafting reactions were carried out according to the following procedure: $\mathrm{U}$-argon-plasma treated PP substrates were immersed in $100 \mathrm{ml}$ TDI/THF solution ( $5 \mathrm{~g}$ TDI and $70 \mathrm{ml} \mathrm{THF}$ ) and stirred for 1 hour at $60^{\circ} \mathrm{C}$. Then $150 \mathrm{ml}$ of PEG/THF/DD solution (1 $\mathrm{g}$ PEG, $30 \mathrm{ml}$ THF and $1 \mathrm{ml} \mathrm{DD}$ ) was added and the mixture was kept an additional hour at $60^{\circ} \mathrm{C}$. The PP samples were then removed from the solution and oven cured for 35 hours at $95^{\circ} \mathrm{C}$. Then the polyurethane grafted substrates were THF-extracted, dried and stored for analytical purposes.

Plasma Treatment: Surface modifications of PP substrates were performed in a capacitively coupled, $50 \mathrm{kHz}$, stainless steel plasma-reactor described earlier [4,5]. In a typical experiment $\mathrm{M}$ - or Ucoated PP substrates were positioned on the lower, grounded-electrode, then base pressure was established, and by operating proper flow controllers and valves the treatment-argon-pressure was created in the reactor. The Ar-plasma was then ignited and sustained at the desired RF-power for the preselected time period. At the end of the reaction the PP-samples were removed from the reactor, washed in hot water, dried in vacuum oven, and stored for analytical purposes and for post-plasma treatment operations. The following experimental conditions were used during the plasma treatments: base pressure: $50 \mathrm{mT}$; pressure in the absence of plasma: $100 \mathrm{mT}$; RF-power dissipated to the electrodes: 100 $\mathrm{W}$; argon flow rate: $6.0 \mathrm{sccm}$; treatment time: $0.5-10$ minutes; temperature of the substrate: $25^{\circ} \mathrm{C}$.

\section{RESULTS AND DISCUSSIONS}

LEE-MS plasma induced fragmentation of $M$ and $U$ are presented in Fig. 2 and Fig. 3. It can be noticed that the M-origin main ion-molecular fragments are $\mathrm{m} / \mathrm{z}=85$ and 84 , and $\mathrm{m} / \mathrm{z}=42$ and 41 , beside the molecular-ion $(\mathrm{m} / \mathrm{z}=126)$, which suggest an electron induced splitting of $=\mathrm{C}\left(\mathrm{NH}_{2}\right)-\mathrm{N}=$ units. It is noteworthy that the intensity of 41 fragment is significantly higher than that of 42 indicating the simultaneous presence of intense dehydrogenation processes. The multi-free-radical species resulted from $m / z=85,84,42$ and 43 ions will probably recombine on plasma activated PP surfaces giving rise to the implantation of $-\mathrm{NH}_{2}$ and $=\mathrm{NH}$ functionalities. The fragmentation pattern of $\mathrm{U}$ is sensibly different for that of $M$. Only one major ion-molecular fragment $(\mathrm{m} / \mathrm{z}=44)$ can be identified in the spectrum in addition to the molecular ion $(\mathrm{m} / \mathrm{z}=60)$. Primary amine and amide functionalities are the results of dissociation mechanisms. It also can be noticed that the dehydrogenated correspondents of amide-type fragments are less abundant in the molecular fragment mixture. Radical species resulted from the plasma-generated dissociation of $\mathrm{U}$ will probably lead to the implantation onto substrate surfaces of $=\mathrm{NH},-\mathrm{NH}_{2}$, and $-\mathrm{C}\left(\mathrm{NH}_{2}\right)=\mathrm{O}$ functionalities. MS-electron and plasma-induced molecular fragmentation mechanisms are certainly not identical, however, significant similarities 


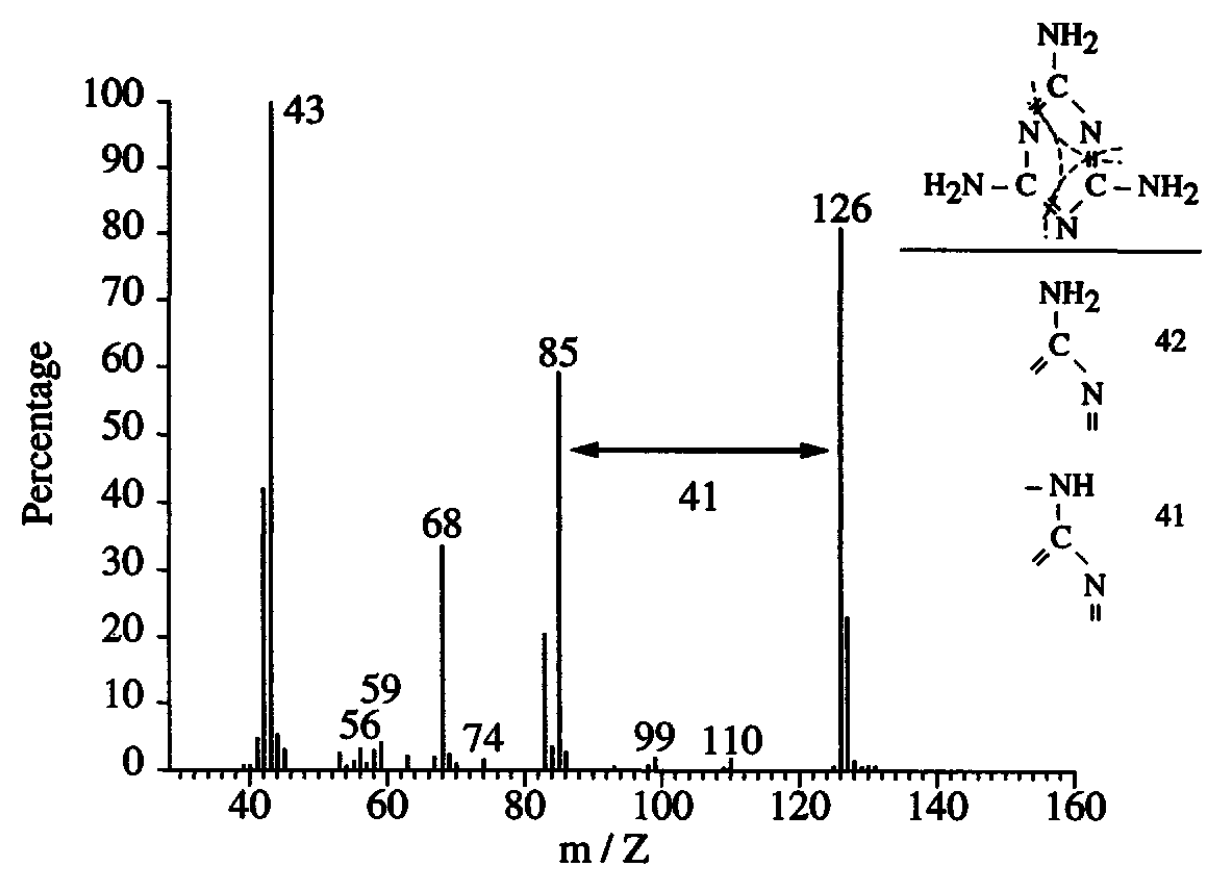

Fig. 2 LEE-MS Fragmentation Pattern of Melamine and the Corresponding Ionic-Fragment Composition.

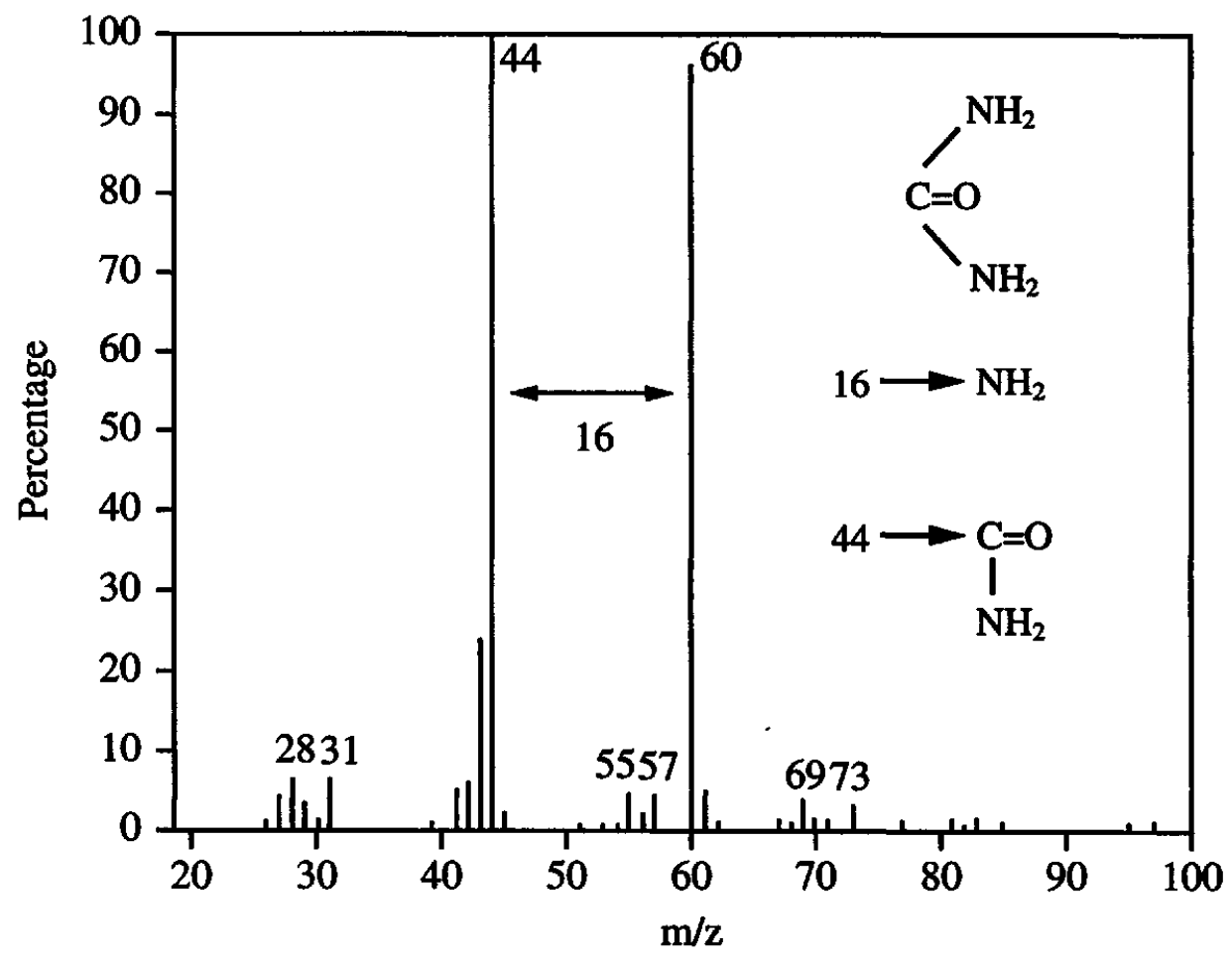

Fig. 3 LEE-MS Fragmentation Pattern of Urea and the Corresponding Ionic- Fragment Composition. 
have been found between the two processes $[37,2,5,6]$. Some similarities between the plasma induced $M$ and $U$ based processes should not be excluded due to the possible synthesis of $M$ from $U$ according to the following reaction:

$$
6 \mathrm{OC}\left(\mathrm{NH}_{2}\right)_{2} \rightarrow \mathrm{C}_{3} \mathrm{~N}_{3}\left(\mathrm{NH}_{2}\right)_{3}+6 \mathrm{NH}_{3}+3 \mathrm{CO}_{2}
$$

The ammonia-origin hydrogen might also enhance the formation of primary amine structures.

Surface functionalization of PP from M/A-plasma: ATR-FTIR spectra of untreated and M/Aplasma treated PP substrates are presented in Fig. 4 and Fig. 5. It can be observed that besides the peculiar C-H stretching (2913 and $\left.2948 \mathrm{~cm}^{-1}\right)$ and deformation $\left(\mathrm{CH}_{2} 1457\right.$ and $\left.\mathrm{CH}_{3} 1376 \mathrm{~cm}^{-1}\right)$ vibration of virgin $P P$ the presence of relatively intense $=C=C=\left(1620-1650 \mathrm{~cm}^{-1}\right)$ non-conjugated stretching vibration and $=\mathrm{C}=\mathrm{O}\left(1737 \mathrm{~cm}^{-1}\right)$ stretching absorption can be identified in the case of plasma modified PP substrates. The $=\mathrm{C}=\mathrm{O}$ functionalities have probably a post-plasma ex-situ oxidation origin. It has been shown in earlier experiment that plasma generated surface-free-radicals disappear at a very high rate under open laboratory conditions [38]. It is noteworthy that existence of $\mathrm{NH}$ stretching absorption both for primary and secondary (or imine) groups $\left(3200-3500 \mathrm{~cm}^{-1}\right)$, and the presence of intense deformation vibrations $\left(1550-1650 \mathrm{~cm}^{-1}\right)$ belonging to the same functionalities and/or primary amides, also can be evidenced. This findings clearly indicate the presence of $\mathrm{NH}_{\mathrm{X}}$ groups on the plasma treated PP surfaces.

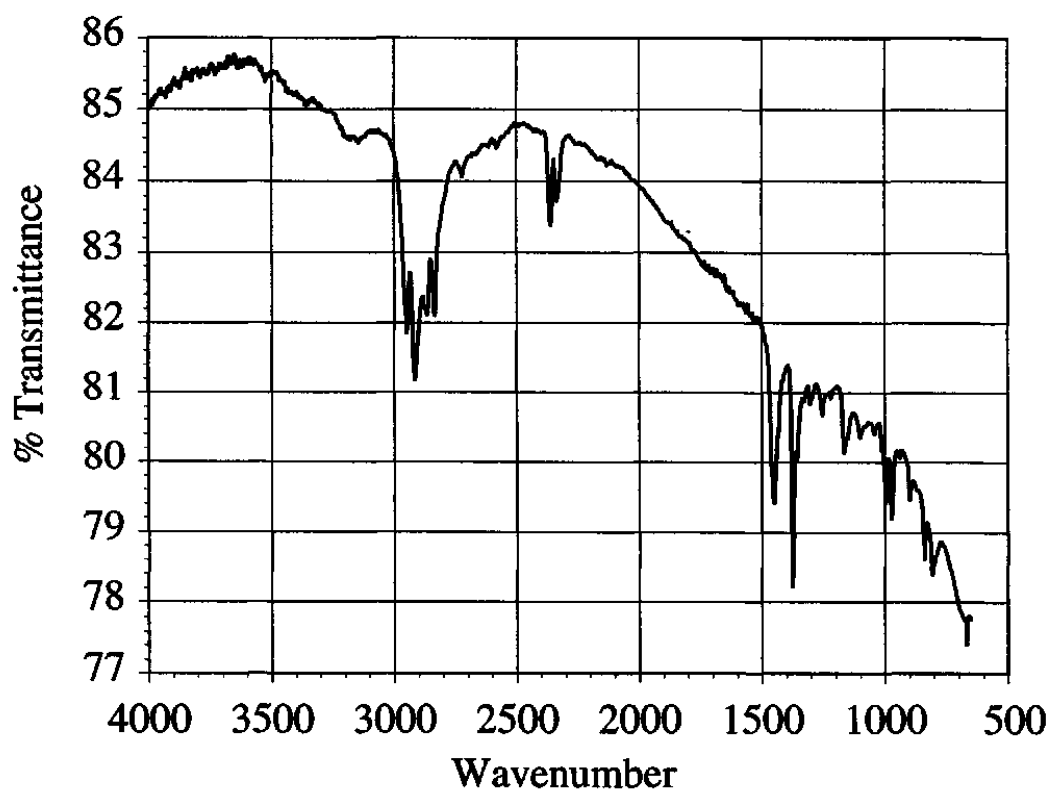

Fig. 4 FTIR Spectrum of Untreated Polypropylene Fabric 


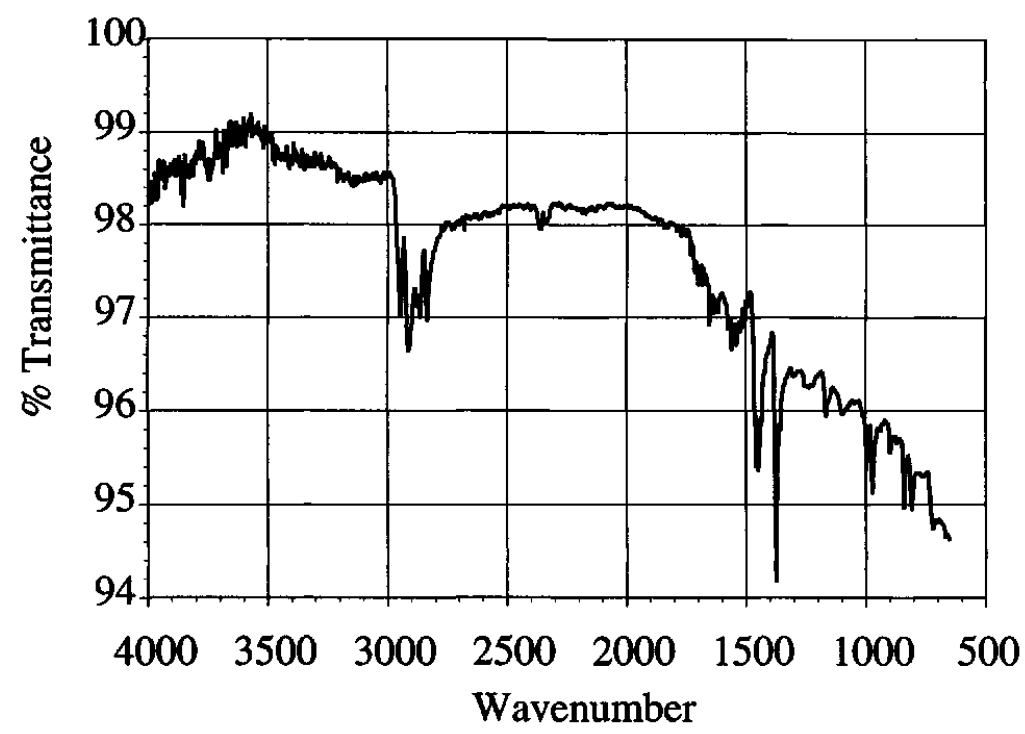

Fig. 5 FTIR Spectrum of Melamine Plasma Treated Polypropylene Fabric (100 mTorr, $100 \mathrm{~W}$, $10 \mathrm{~min})$.

Survey (Fig. 6) and high-resolution (HR) ESCA data (Figure 7) substantiate the conclusions from infra-red measurements. Besides carbon, the presence of a relatively high nitrogen (14\%) and oxygen $(14 \%)$ atomic concentrations can be identified in the surface layers of plasma treated (100 W; $100 \mathrm{mT} ; 10$ minutes) PP substrates. The non-equivalent carbon linkages estimated from HR-C1s binding energy region (Fig. 7) exhibit a trimodal pattern. All assignments of binding energy values were performed according to the Scienta ESCA 300 Database [39]. By comparing specific biding energy values from poly-methacrylamide $\left(-(\mathrm{O}) \mathrm{C}^{*}-\mathrm{NH}_{2} ; 288.3 \mathrm{eV}\right)$, poly-urea $\left(-(\mathrm{NH})_{2} \mathrm{C}^{*}=\mathrm{O}\right.$; $288.8 \mathrm{eV})$, Nylon $66\left(-\left(\mathrm{CH}_{2}\right)(\mathrm{NH}) \mathrm{C}^{*}=\mathrm{O} ; 288.0 \mathrm{eV}\right)$, and poly-acrylamide $\left(\mathrm{O}=\mathrm{C}^{*}-\mathrm{NH}_{2} ; 288.6 \mathrm{eV}\right)$,

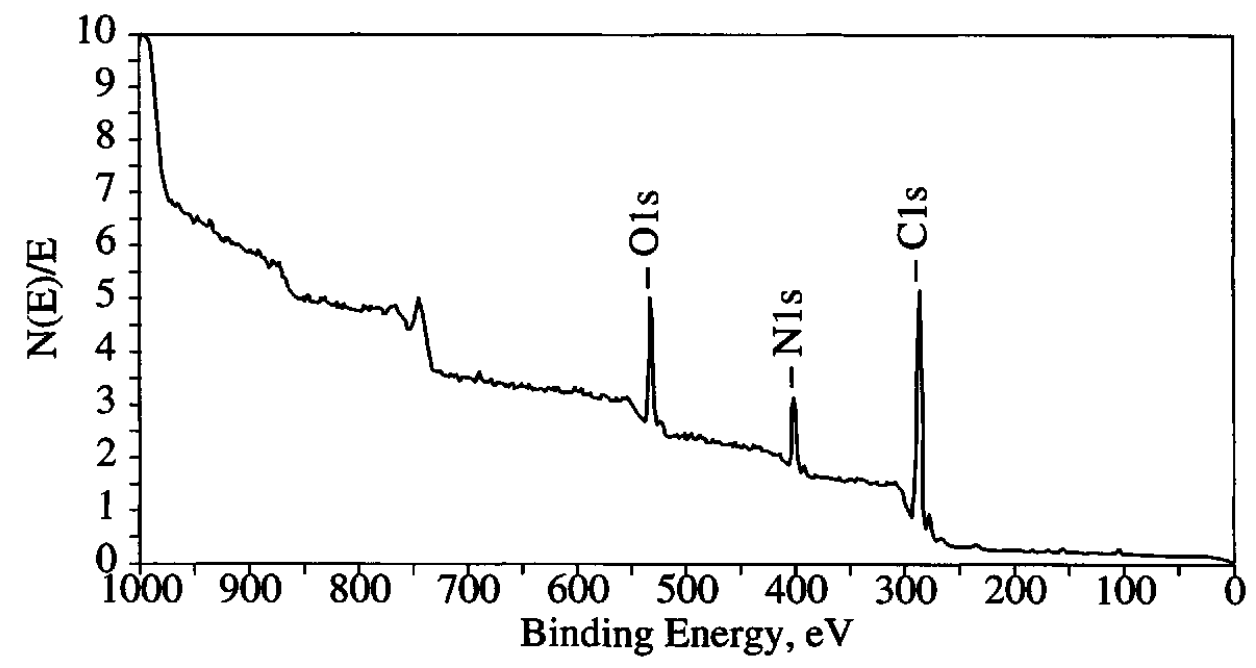

Fig. 6 ESCA Spectrum of Melamine Plasma Treated Polypropylene Fabric (100 mTorr, $100 \mathrm{~W}, 10 \mathrm{~min}$ ). 


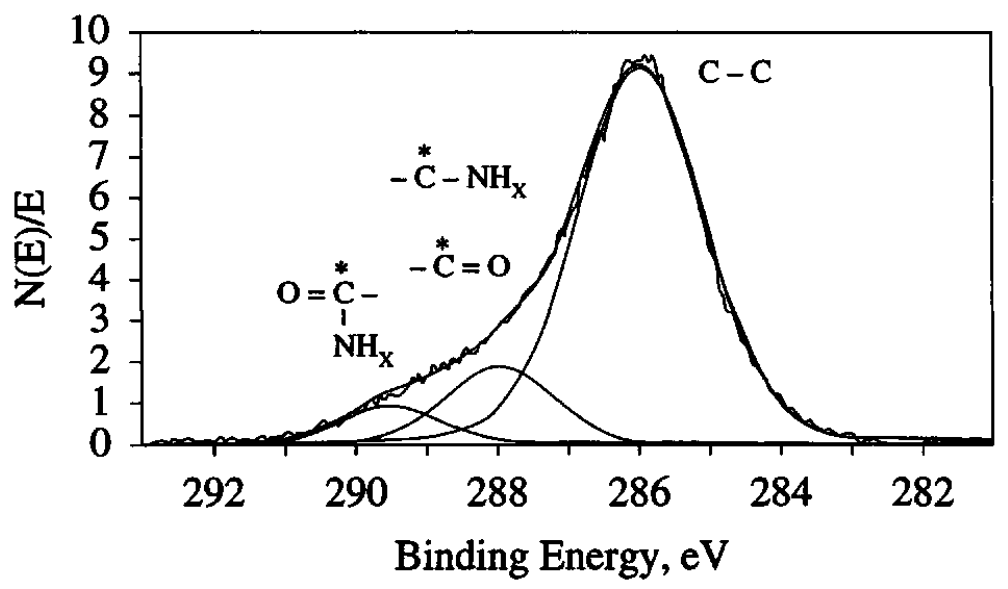

Fig. 7 High Resolution ESCA C1s Signal of Melamine Plasma Treated Polypropylene Fabric (100 mTorr, $100 \mathrm{~W}, 10 \mathrm{~min})$. (Charge-origin binding energy shift $=1 \mathrm{eV}$ )

the highest binding energy value peak $(288.7 \mathrm{eV})$ associated with the plasma treated PP sample was assigned to the $\mathrm{O}=\mathrm{C}^{*}-\mathrm{NH}_{\mathrm{x}}$ functionality. Similarly based on peculiar $\mathrm{C} 1 \mathrm{~s}$ binding energy values from Nylon $6\left(-\left(\mathrm{CH}_{2}\right) \mathrm{C}(\mathrm{O})(\mathrm{NH})-\mathrm{C}^{*} \mathrm{H}_{2}-; 286.0 \mathrm{eV}\right)$, Poly-N-vinylpyrrolidone ( $=\mathrm{C}^{*} \mathrm{H}-\mathrm{N}=; 286.0$ $\mathrm{eV})$ and Poly-allylamine-hydrochloride $\left(-\mathrm{C}^{*} \mathrm{H}_{2}-\mathrm{NH}_{3}{ }^{+} \mathrm{Cl}^{-} ; 286.2 \mathrm{eV}\right)$ the $286.6 \mathrm{eV}$ binding energy value peak has be considered to be related to the presence of $\mathrm{C}-\mathrm{NH}_{\mathrm{x}}$ bonds. However, this region also is characteristic for $\mathrm{C}=\mathrm{O}$ linkages; the possible, simultaneous presence of these functionalities on plasma treated PP surfaces cannot be excluded.

The influence of treatment time on the relative surface atomic composition of M/Arplasma modified PP substrates is presented in Fig. 8 and Fig. 9. It can be noticed that treatment times as short as 1 minute are long enough to reach the highest nitrogen and oxygen surface atomic contents; longer exposure of the substrates to the discharge does not change significantly the relative surface atomic compositions. This data indicate that the most intense structural modifications of the plasma irradiated layers are induced and completed at the very beginning of the plasma treatment process, fol-

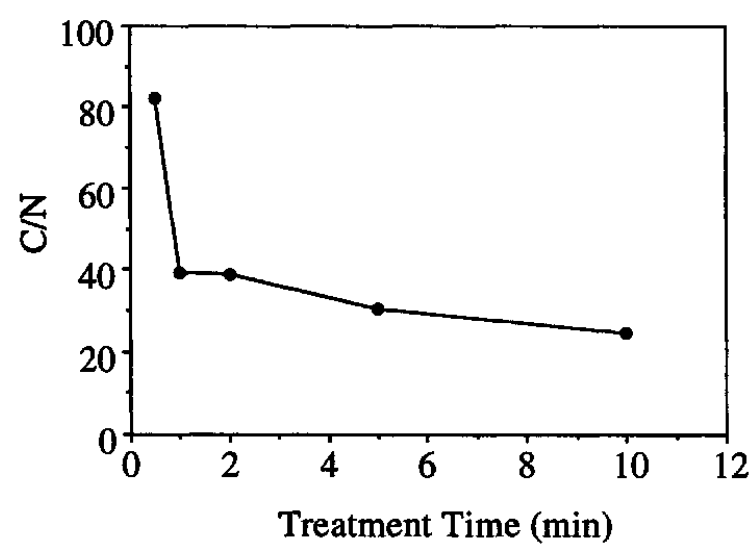

Fig. 8 The Influence of Treatment Time on the Relative Surface Atomic Composition (C/N) of Melamine Plasma Treated Polypropylene Fabric (100 mTorr, $100 \mathrm{~W})$. 


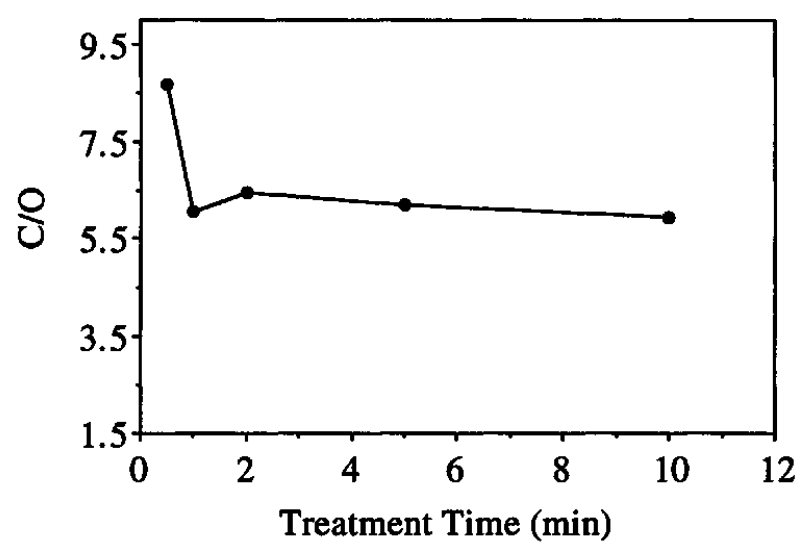

Fig. 9 The Influence of Treatment Time on the Relative Surface Atomic Composition (C/O) of Melamine Treated Polypropylene Fabric (100 mTorr, $100 \mathrm{~W})$.

lowed by the development of an equilibrium reaction between the surface implantation/deposition and ablation mechanisms. These findings are significant for possible technological application of plasma modified films and fabrics where high speed industrial processing are required.

It has been demonstrated that the wettability characteristics of plasma modified substrates are strongly related to the surface atomic compositions (Fig. 10). An important decrease of contact angle can be observed in the first minute treatment time period, followed by a less significant diminuation of this parameter.

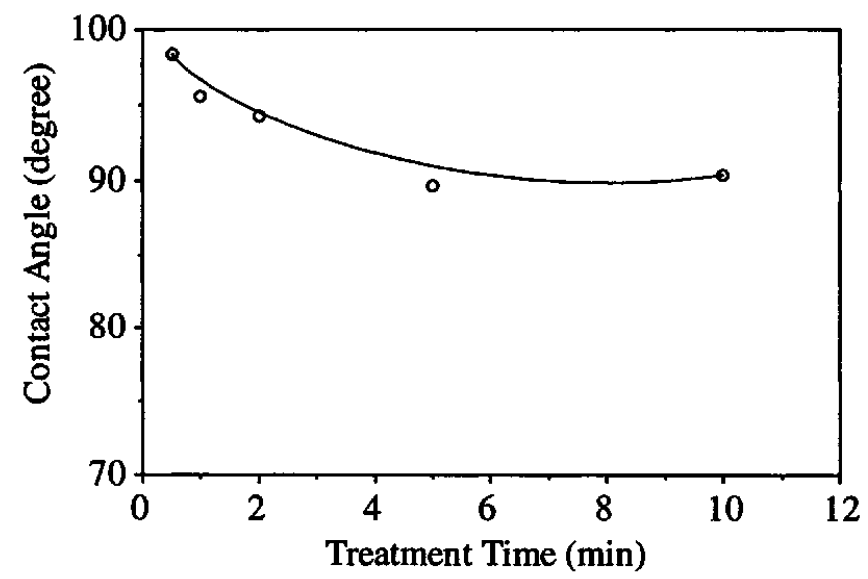

Fig. 10 The Influence of Treatment Time on the Contact Angle of Melamine Plasma Treated Polypropylene Fabric (100 mTorr, $100 \mathrm{~W})$. 
Similarly, primary amine group concentration evaluations from PP sample surfaces indicate the presence of a more intense primary amine implantation for the first period of plasma treatment process (Fig. 11). It is noteworthy that surface primary amine group concentration as high as 10 amine groups $/ \mathrm{nm}^{2}$ can be generated at relatively short treatment times.

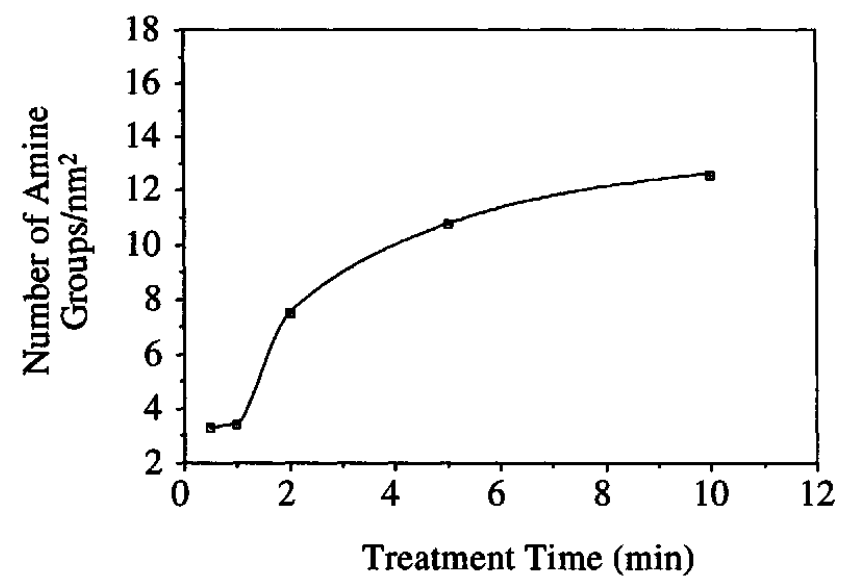

Fig. 11 Primary Amine Group Estimation for Melamine Plasma Treated Polypropylene at Different Treatment Times (150 mTorr, $100 \mathrm{~W})$.

Surface Functionalization of PP from U/A-plasma: Fig. 12, exhibit a typical ATR-FTIR spectrum of U/Ar-plasma treated PP substrate. In addition to the specific absorption of untreated PP an intense and broad absorption can be evidenced in the wavenumber range of $1500-1800 \mathrm{~cm}^{-1}$. This domain overlap both amine, amide and ketone-origin $\mathrm{N}-\mathrm{H}$ and $\mathrm{C}=\mathrm{O}$ deformation vibrations. The stretching

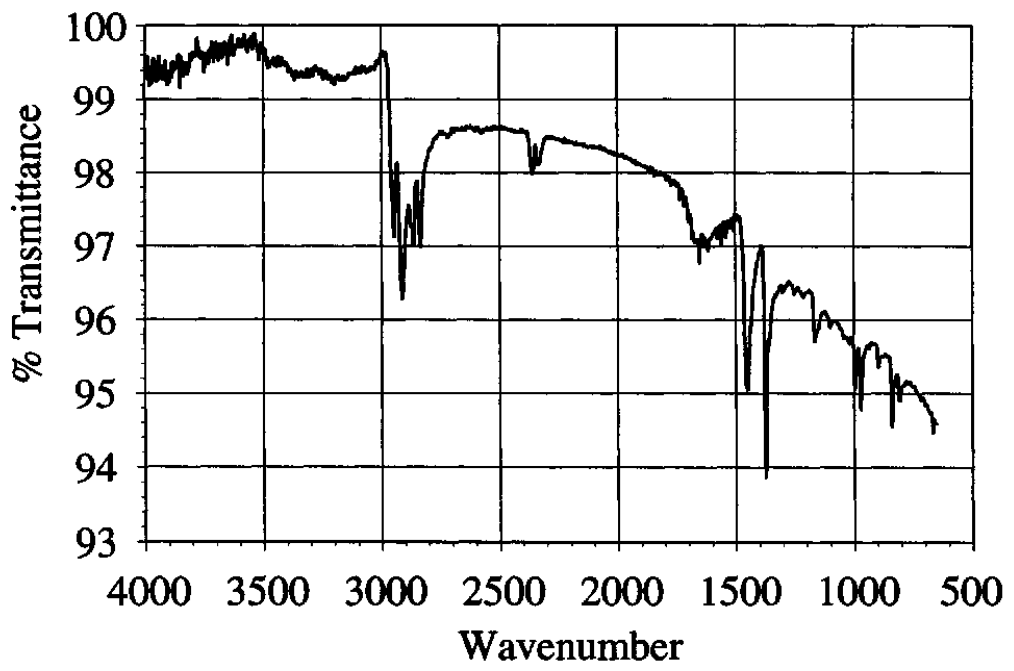

Fig. 12 FTIR Spectrum of Urea Treated Polypropylene (100 mTorr, $100 \mathrm{~W}, 10 \mathrm{~min}$ ). 
region of asymmetric and symmetric primary amines, and those of secondary amines and imines (3200-3500 $\mathrm{cm}^{-1}$ ) also is dominated by a broad absorption. These findings indicate the coexistence of primary and secondary amine, amide and imine-type functionalities. High resolution ATR-FTIR spectra of the wavenumber region of $1200-1800 \mathrm{~cm}^{-1}$ recorded from PP substrates exposed to plasma for various time intervals (Fig. 13) clearly show that longer treatment times induce more intense $\mathrm{N}-\mathrm{H}$ and $\mathrm{C}=\mathrm{O}$ absorption. It also can be observed that the most intense amination reaction undergoes in the first two minutes; longer exposure to the U/A-plasma of PP samples does not change significantly the $\mathrm{NH}_{\mathrm{x}}$ group concentrations.

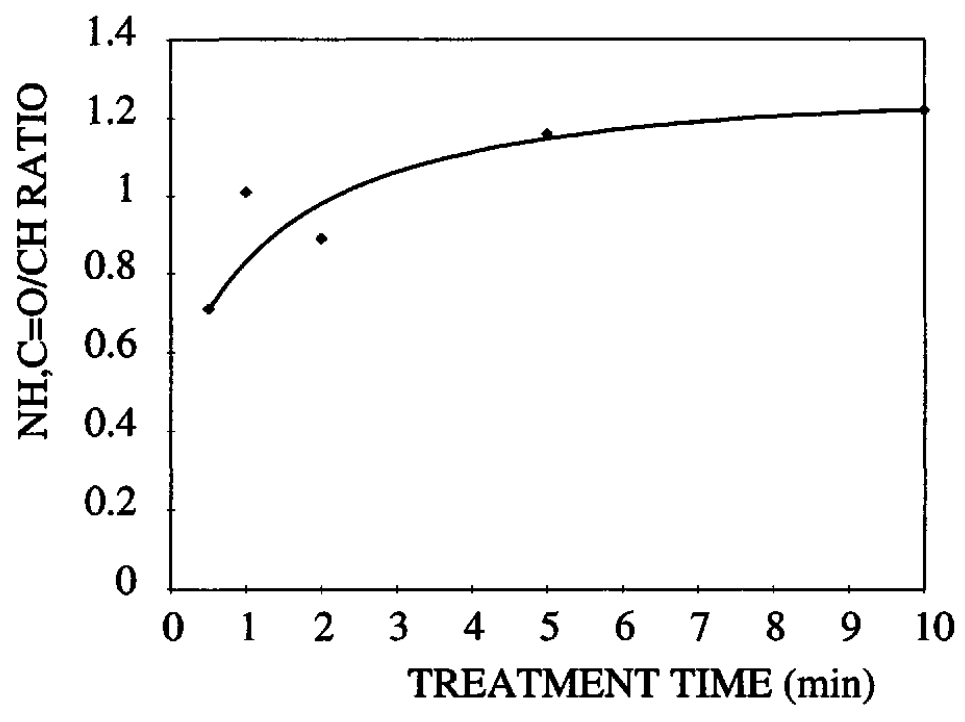

Fig. 13 The Effect of Treatment Time on the NH, $\mathrm{C}=\mathrm{O} / \mathrm{CH}$ Ratio Based on High Resolution ATR-FTIR (100 mTorr, $100 \mathrm{~W}$ )

Survey (Fig. 14) and HR-(Fig. 15)-ESCA data derived from U/A-plasma treated PP also indicate the presence of $\mathrm{NH}_{\mathrm{x}}$ and/or $-\mathrm{C}=\mathrm{O}\left(\mathrm{NH}_{\mathrm{x}}\right)$ functionalities on the substrate surfaces. However, in this case a higher oxygen (21\%) and nitrogen (17\%) content can be observed in comparison to the M/Ardischarge modified samples. This can probably be attributed to the presence of $\mathrm{U}$-origin $-\mathrm{C}=\mathrm{O}\left(\mathrm{NH}_{2}\right)$ fragments in the plasma generated mixture of gaseous-phase active species. Similarly to the Mtreated samples the HR ESCA diagram of $\mathrm{C} 1 \mathrm{~s}$ region exhibit a trimodal pattern and the non-equivalent carbon atoms were identified as $\mathrm{O}=\mathrm{C}^{*}\left(\mathrm{NH}_{\mathrm{x}}\right)(288.6 \mathrm{eV})$, and $-\mathrm{C}^{*}\left(\mathrm{NH}_{\mathrm{x}}\right)(287 \mathrm{eV})$ based on database-spectra.

The influence of treatment time on the relative surfaces atomic composition of U/Ar-plasma modified samples indicate a similar behavior for the $\mathrm{C} / \mathrm{N}$ ratios (Fig. 16) and a different pattern for the $\mathrm{C} /$ $\mathrm{O}$ ratios (Fig. 17) in comparison to the $\mathrm{M} / \mathrm{U}$-plasma treated substrates. The most intense nitrogen up- 


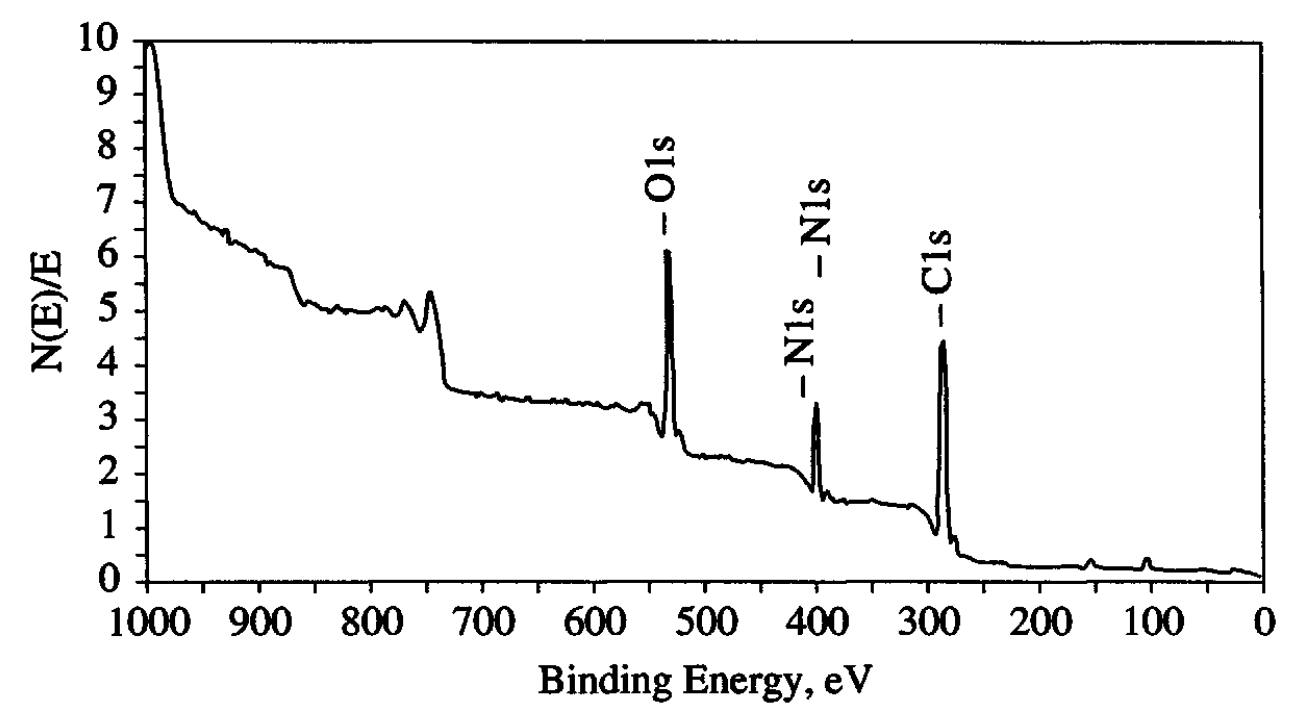

Fig. 14 ESCA Spectrum of Urea Plasma Treated Polypropylene Fabric (100 mTorr, $100 \mathrm{~W}, 10 \mathrm{~min})$.

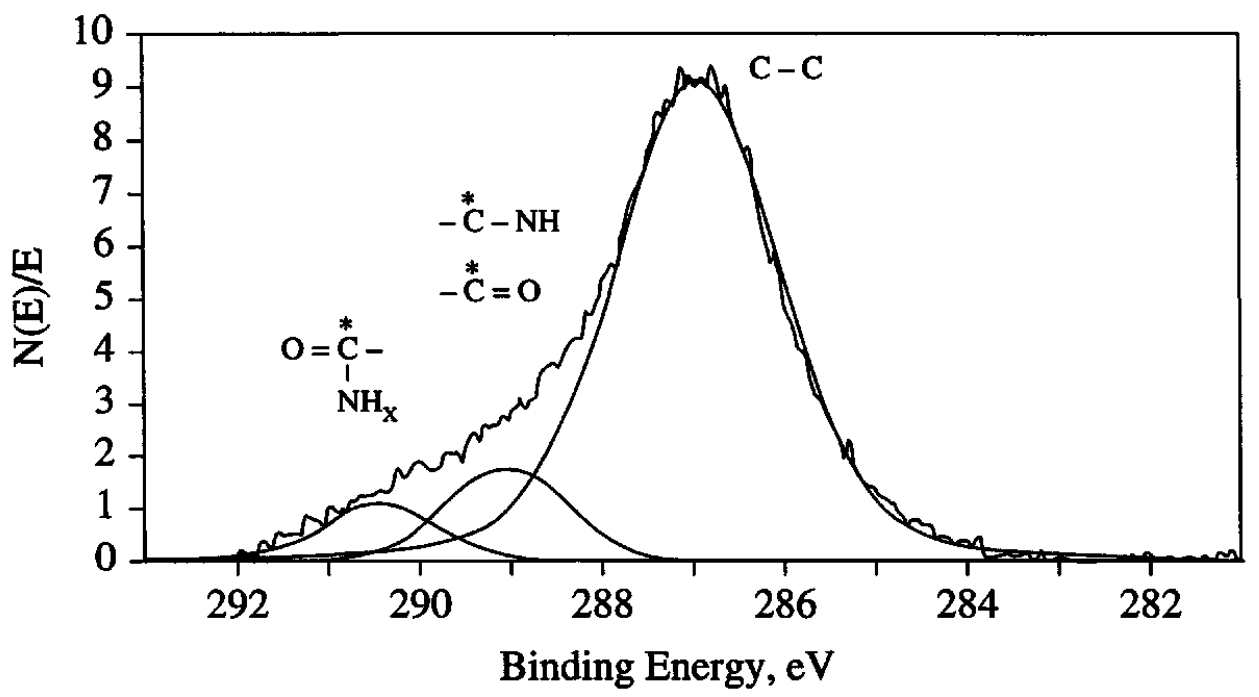

Fig. 15 High Resolution ESCA C1s Signal of Melamine Plasma Treated Fabric (100 mTorr, $100 \mathrm{~W}, 10 \mathrm{~min}$ ) (Charge origin binding energy shift $=2 \mathrm{eV}$ )

take is recorded in the first few minutes, followed by a less significant nitrogen accumulation in the surface layers at longer treatment time periods. The slight increase of oxygen concentration at longer plasma-exposes (5 minutes and longer) can probably be related to the intrinsic oxygen content of $U$.

The influence of treatment time on the surface concentration of primary amine functionalities from U/Ar-plasma modified PP samples is shown in Fig. 18. Similarly to the M/Ar-plasma derivatized 


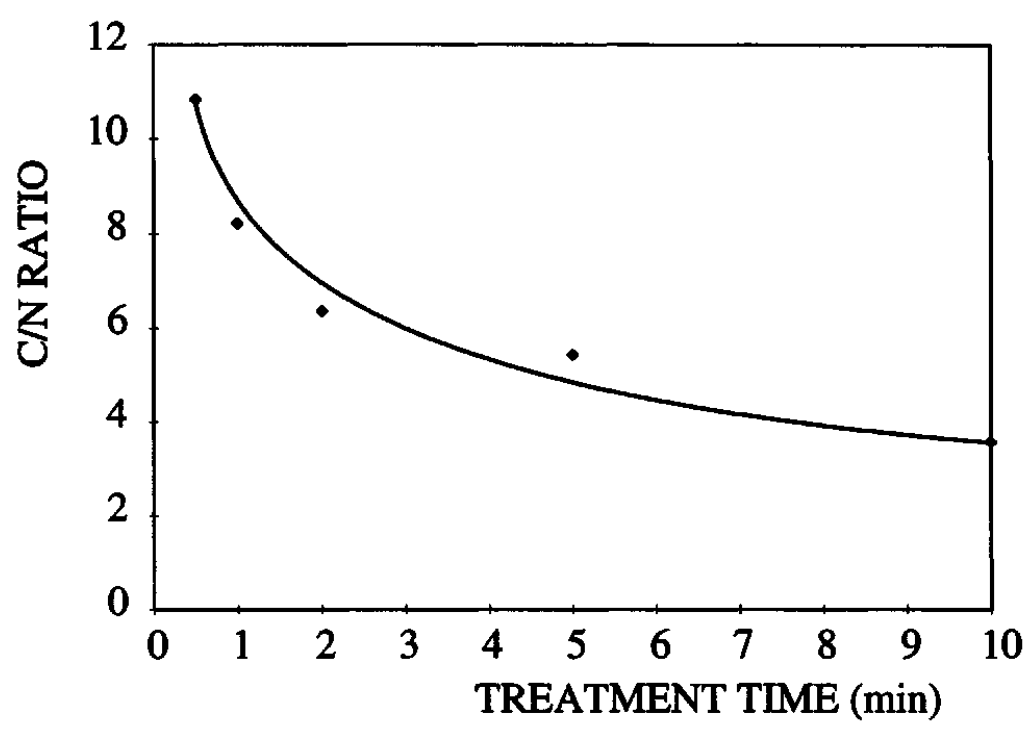

Fig. 16 The Effect of Treatment Time on the Relative Surface Atomic Composition $(\mathrm{C} / \mathrm{N})$ of Urea Plasma Treated Polypropylene Fabric (100 mTorr, $100 \mathrm{~W}$ ).

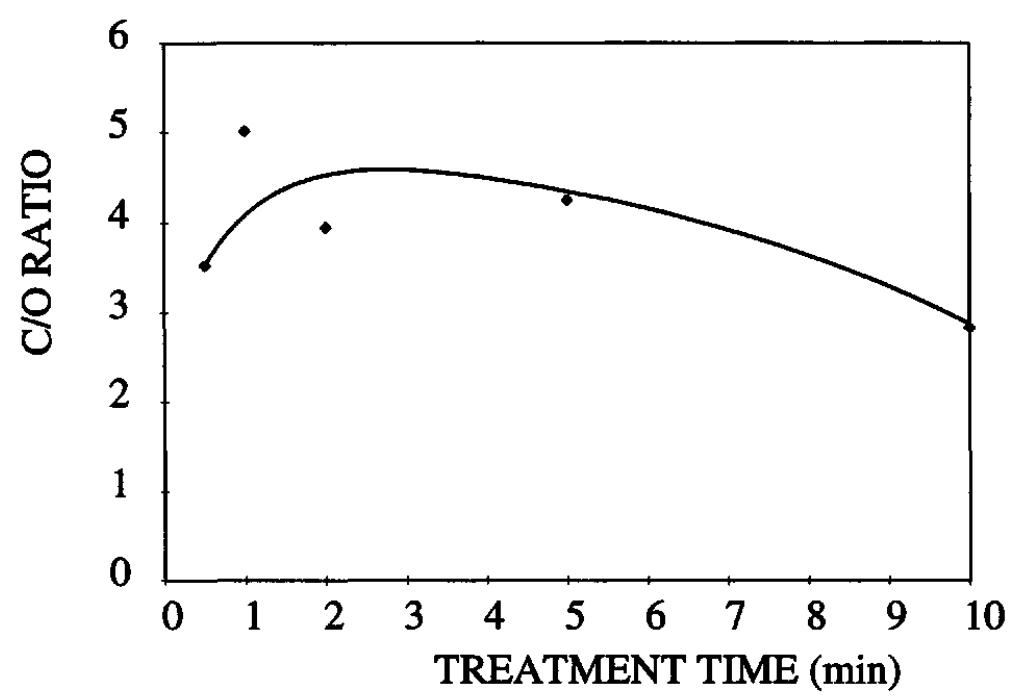

Fig. 17 The Effect of Treatment Time on the Relative Surface Atomic Composition (C/O) of Urea Plasma Treated Polypropylene Fabric.

surfaces a more intense amine group implantation can be remarked in the first minutes. Plasma exposures longer than 3 minutes induce a steady increase of primary amine concentration according to a linear relationship. It is noteworthy that amine concentrations significantly higher (over $25 \%$ at 10 minutes treatment time) than those recorded in the case of M/Ar-plasma can be achieved by using $\mathrm{U}$. 


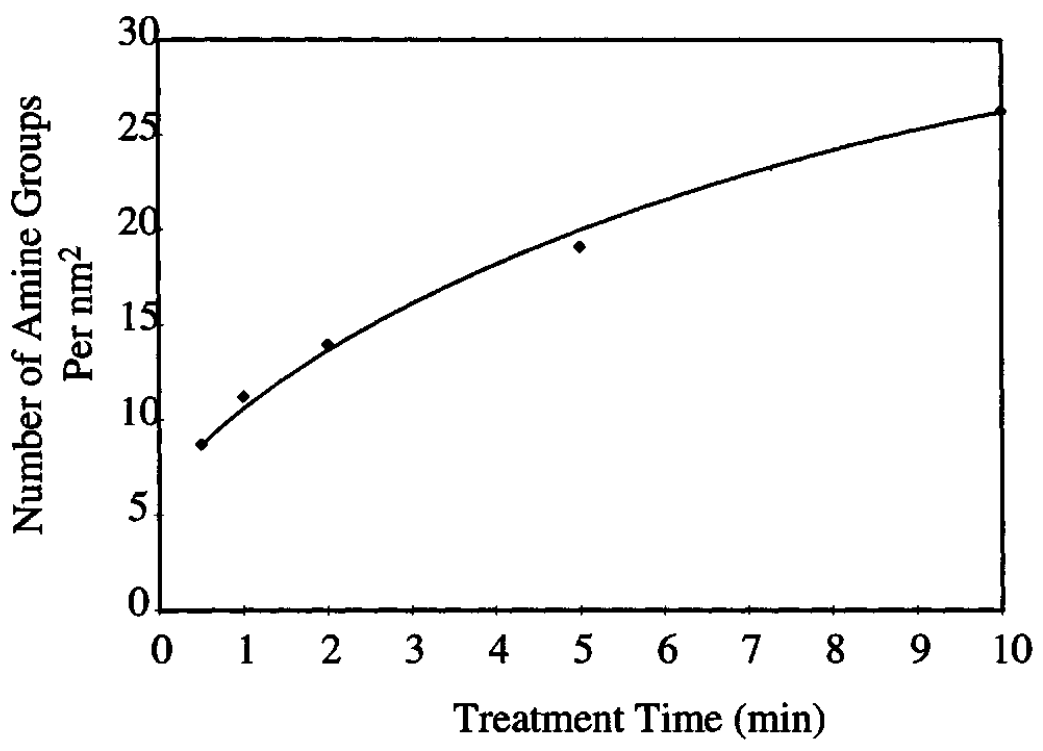

Fig. 18 Primary Amine Group Estimation for Urea Plasma Treated Polypropylene Fabric (100 mTorr, $100 \mathrm{~W}$ ).

TDI and PEG based graft-polymerization reactions successfully developed from plasma functionalized PP surfaces (Fig. 19, Table 2) substantiate the conclusion that primary amine group implantation onto PP surfaces under U/A-RF-plasma conditions can efficiently be developed. A good agreement can be observed between the relative surface atomic composition of polyurethane (PU) grafted PP surfaces and the theoretical relative atomic composition of PU. Deconvoluted C1s-HR-ESCA spectrum recorded from U/A-plasma- treated and PU-grafted PP sample surfaces is practically identical

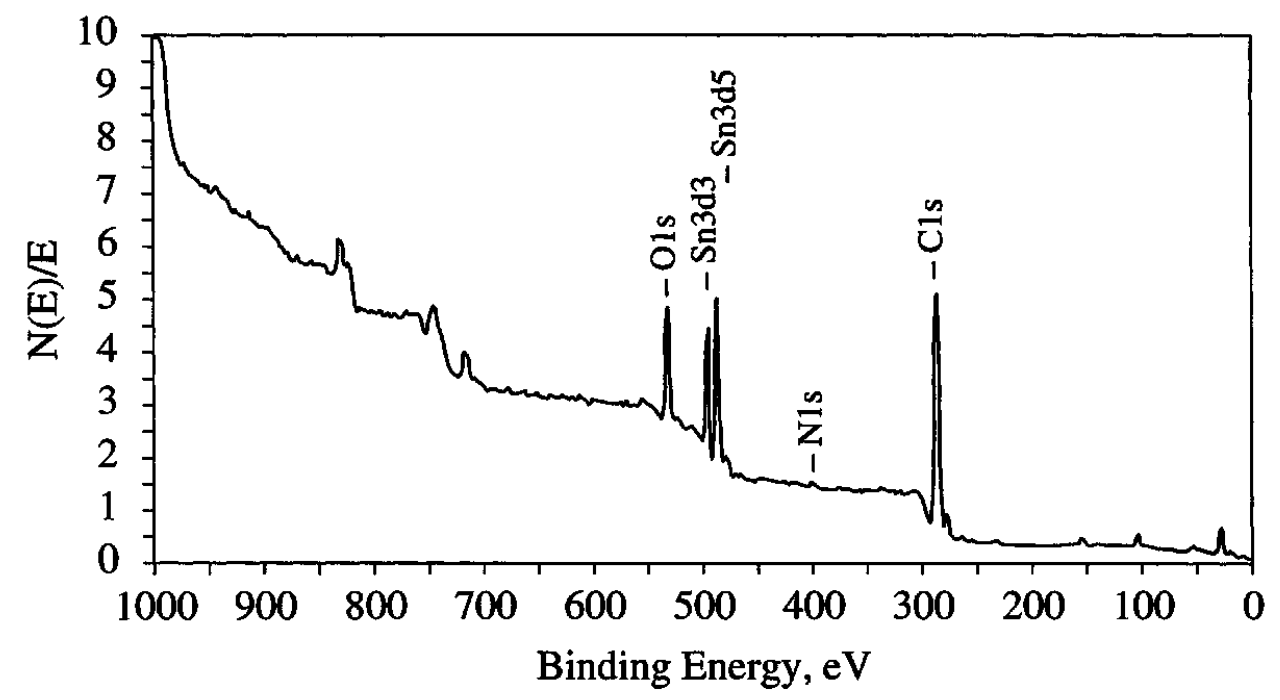

Fig. 19 ESCA Survey of Polyurethane Grafted Urea Plasma Treated Fabric (100 mTorr, $100 \mathrm{~W}, 10 \mathrm{~min}$ ). 
Table 2. Relative Surface Atomic Composition of PUgrafted Polypropylene, PU and U/Ar-Plasma Treated PP.

\begin{tabular}{crrr}
\hline & $\% \mathrm{~N}$ & $\% \mathrm{O}$ & $\% \mathrm{C}$ \\
\hline PU-grafted PP & 2.7 & 7.0 & 90.3 \\
PU & 2.3 & 4.8 & 92.9 \\
U/Ar-Plasma Treated & 17.9 & 21.1 & 61.0 \\
PP & & & \\
\hline
\end{tabular}

with that of the data-base PU spectrum (Figures 20 and 21). This clearly indicate that the PP surfaces were efficiently coated through graft-polymerization reactions by PU layers. The much higher surface areas of $\mathrm{CH}_{2}$ peaks recorded in the case of plasma treated and grafted samples are related to the use of high molecular weight PEG.

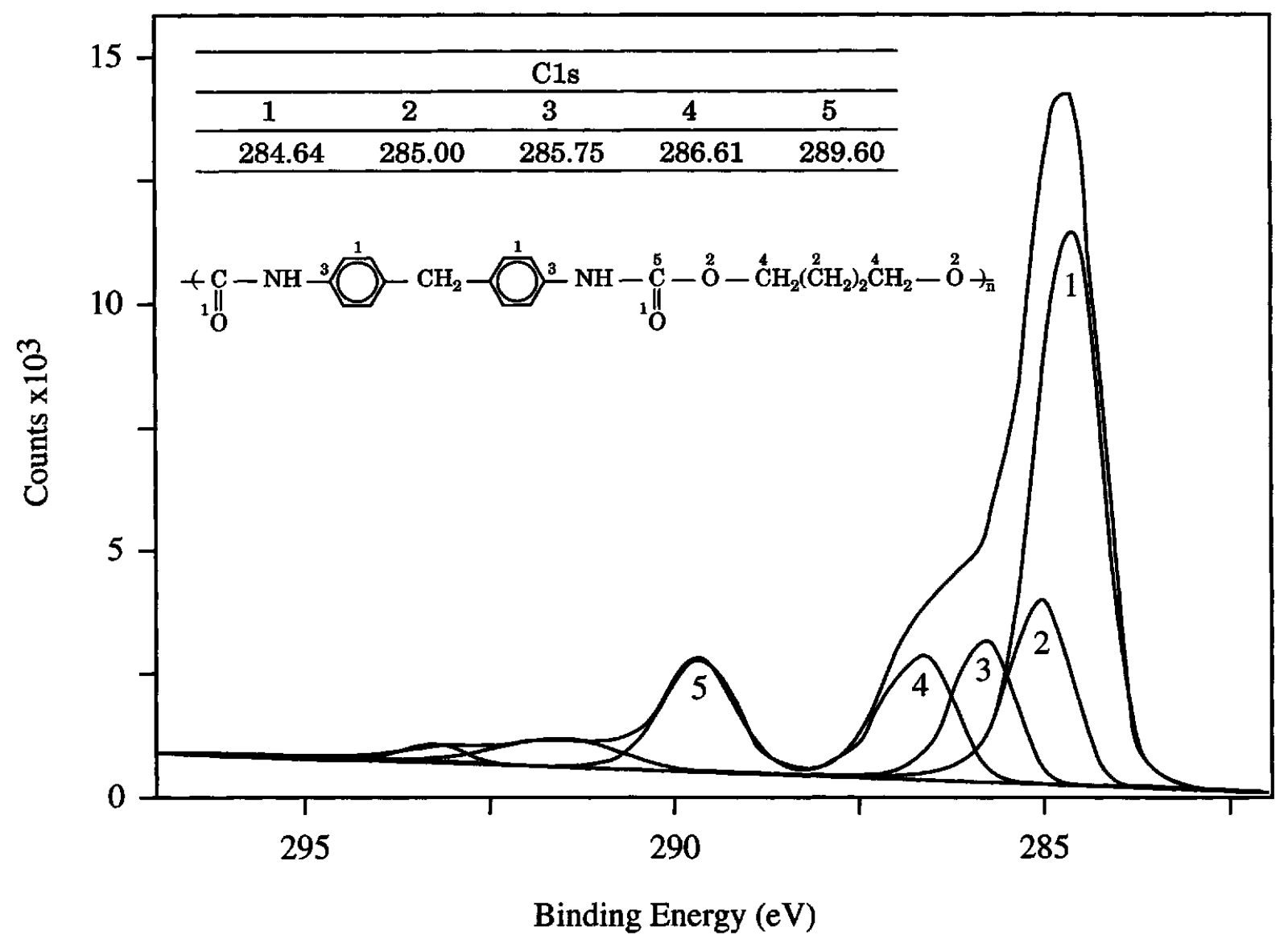

Fig. 20 High Resolution ESCA C1s Signal of Standard Polyurethane. 


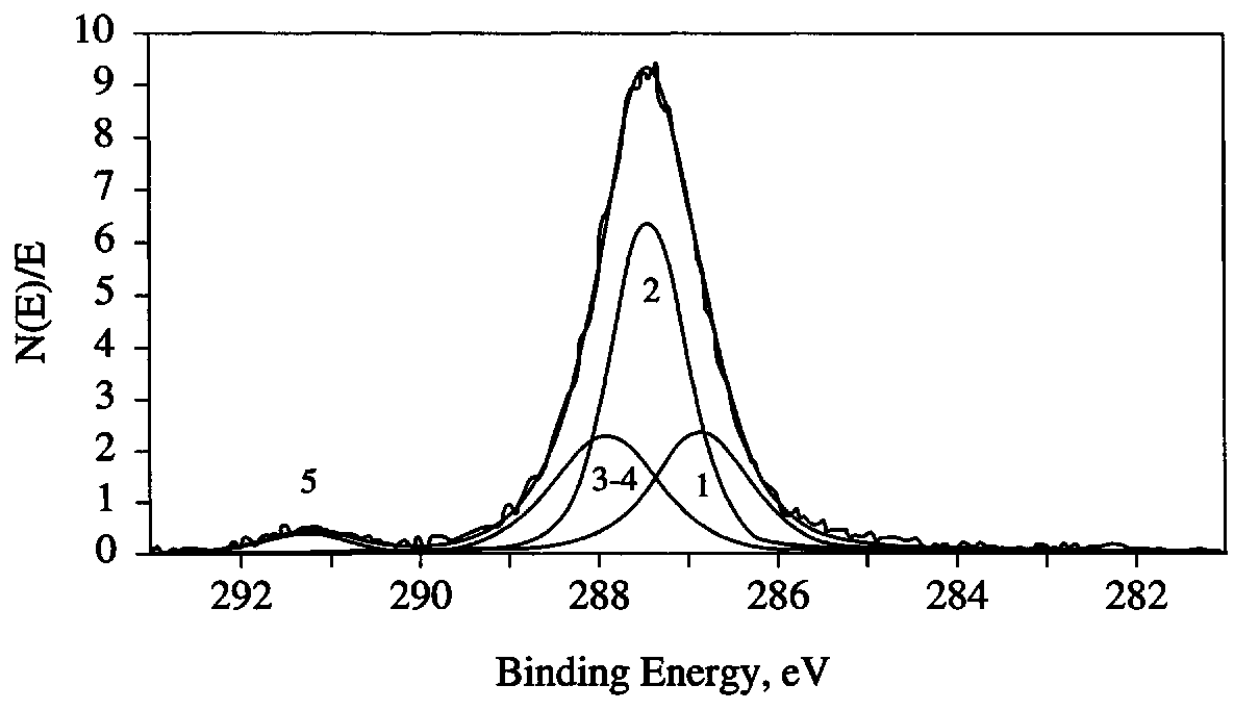

Fig. 21 High Resolution ESCA C1s Signal of Polyurethane Grafted Urea Plasma Treated Polypropylene Fabric (100mTorr, $100 \mathrm{~W}, 10 \mathrm{~min})$.

\section{CONCLUSIONS}

- It has been demonstrated that simultaneous plasma induced evaporation and fragmentation of $\mathbf{M}$ and $\mathrm{U}$, and implantation of primary amine groups onto PP surfaces, are possible from $\mathrm{M}$ and $\mathrm{U}$ pre-coated and Ar-plasma exposed PP surfaces;

- It has been shown that plasma-treatment times as short as 2 minutes are enough to generate relatively high primary amine concentrations;

- Evaluation of relative surface atomic compositions also indicate that the discharge chemistry on PP surfaces is completed almost totally in the first interval of the plasma exposure;

- Successful grafting reactions developed from plasma derivatized PP surfaces permit to envisage significant applications of this novel technique.

\section{ACKNOWLEDGMENT}

Financial support from the USDA, Southern Regional Project S 250, Engineering Research Center for Plasma Aided Manufacturing (NSF Grant No. ECD 8721545), and the UW-Graduate School is gratefully acknowledged. 


\section{REFERENCES}

1. F. Denes, Z.Q. Hua, C.E.C.A. Hop, and R.A. Young, J. Appl., Polym. Sci., (accepted), (1995).

2. Z.Q. Hua, F. Denes, and R.A. Young, Journal of Vacuum Society, (accepted), (1995).

3. F. Denes, D. Feldman, .Q. Hua, Z. Zheng, and R.A. Young, Journal of Adhesion Science and technology, (accepted), (1995).

4. F. Denes, Z.Q. Hua, E. Barrios, and R.A. Young, Journal of Macromolecular Science, Pure and Applied Chemistry, A32(8\&9), p. 1405, (1995).

5. A.M. Sarmadi, T.H. Ying, and F. Denes, European Polymer Journal, vol. 31, No. 9, p. 847, (1995).

6. T.H. Ying, A. M. Sarmadi, C.E.C.A. Hop, and F. Denes, Journal of Applied Polymer Science, Vol. 55, p. 1537, (1995).

7. F. Denes, Z.Q. Hua, R.A. Young, and J.L. Shohet, Plasma and Polymers, (submitted-January, 1996).

8. R. d'Agostino, Plasma deposition, Treatment and Etching of Polymers, Academic Press, New York (1990).

9. H.V. Boenig, Plasma Science and Technology, Cornell University, Ithaca, New York, (1982).

10. M. Shen, Plasma Chemistry of Polymers, Marcel Dekker Inc., Basel, New York, (1976).

11. D.T. Clark, A. Dilks, and D. Shuttleworth, The Application of Plasmas to the Synthesis and Surface Modification of Polymers, Chapter 9, in: Polymer Surfaces, D.T. Clark and W.J. Feast eds., John Wiley \& Sons, Chichester, New York, Brisbane, Toronto, (1978).

12. K.L. Mittal, ed., Polymer Surface Modification: Relevance to Adhesion, Part 1. Plasma Surface Modification Techniques, VSP-International Science Publishers, (1995).

13. R. Yoshima, K. Morimoto, A. Nakajima, Y. Ikada, and T. Suzuki, eds., Adhesion and Bonding in Composites, Chapters: 3 and 4, Marcel Dekker, New York Basel, (1990).

14. C-M. Chang, Polymer Surface Modification and Characterization, Chapters: 5-7, Hanser Publishers, Munich, Vienna, New York, (1994).

15. M. Strobel, C.S. Lyons, and K.L. Mittal, Plasma Surface Modification of Polymers: Relevance to Adhesion, VSP-International Science Publishers, (1994).

16. D.C. Carbaugh, F.J. Munno, and J.M. Marchello, Journal of Chemical Physics, vol. 47, No. 12, p. 5211, (1967).

17. P.K. Ghosh and E.J. Bair, Journal of Chemical Physics, 45, p. 4738, (1966).

18. M.H. Hanes and E.J. Bair, Journal of Chemical physics, 38, p. 672, (1963).

19. R. d'Agostino, F. Cramarossa, S. De Benedictis, and G. Ferraro, Plasma Chemistry and Plasma Processing, vol.1, No. 19, (1981).

20. T.L. Ward and R.R. Benerito, Textile Research Journal, April, p. 256, (1982).

21. J. Lub, F.C.B.M. van Vroonhoven, and E. Bruninx, Polymer, vol. 30, p. 40, (1989).

22. S. Holmes and P. Schwartz, Composites Science and Technology, 38, p. 1, (1990).

23. J.R. Hollahan and B.B. Stafford, Journal of Applied Polymer Science, 13, p. 807, (1969).

24. T.R. Gegenbach, X. Xie, R.C. Chatelier, H.J. Griesser, Journal of Adhesion Science and Technology, 8, p. 305, (1994).

25. F. Arefi, M. Tatoluian, V. Andre, J. Amoroux, G. Lorang, in: Mettalized Plastics 3: Fundamental and Applied Aspects, K.L. Mittal Ed., Marcel Dekker, (1992).

26. N. Nakayama, T. Takahagi, F. Soeda, K. Hatada, S. Nagaoka, J. Suzuki and A. Ishitani, Journal of Polymer Science, Polym. Chem. Ed., 26, p. 559, (1988).

27. J.R. Hollahan and T. Wydeven, Science, 179, p. 500, (1973). 
28. D. Peric, A.T. Bell and M. Shen, Journal of Applied Polymer Science, 21, p. 2661, (1977).

29. H. Yasuda, M.O. Bumgarner, H.C. Marsh and N. Morosoff, Journal of Applied Polymer Science: Polymer Chemistry Edition, 14, p. 195, (1976).

30. W.R. Gombotz, W. Guanghui, and A.S. Hoffman, Journal of Applied Polymer Science, 37, p. 91, (1989).

31. W.R. Gombotz and A.S. Hoffman, Journal of Applied Polymer Science: Applied Polymer Symposium, 42, p. 285, (1988).

32. J. Sakata and M. Wada, Journal of Applied Polymer Science, 35, p. 857, (1988).

33. A.M. Sarmadi, F. Denes, and T.H. Ying, abstract, 207th ACS National meeting and Exposition, Cellulose, Paper and Textile Division, San Diego, California, (1994).

34. J.A. Chinn, B.D. Rattner, T.A. Horbett, Biomaterials, 13(5), p. 322, (1992).

35. J.G.A. Terlingen, L.M. Brenneisen, H.T.J. Super, A.P. Pijpers, A.S. Hoffman, and J. Feijen, Journal of Biomaterial Science, Pol. Ed., 4, p. 165, (1993).

36. R. d'Agostino, M. Stendardo and P. Favia, Proceedings of the 12th International Symposium on Plasma Chemistry, Minneapolis, MN-1995, vol. 1, p. 27, (1995).

37. F. Denes, A.M. Sarmadi, C.E.C.A. Hop, and R. Young, Journal of Applied Polymer Science: Applied Polymer Symposium, 54, p. 55, (1994).

38. H.S Sabharwal, F. Denes, L. Nielsen, and R.A. Young, J. Agric. Food Chem., 41, p. 2202, (1993).

39. G. Beamson and D. Briggs, High resolution XPS of Organic Polymers- The Scienta ESCA300 Database, John Wiley \& Sons, Chichester, New York, Brisbane, Toronto, Singapore, (1992). 